\title{
Relevance of Mother Tongue National Examinations to Mother Tongue Curriculum (Syllabus) and Textbooks: The Case of Wolaita Language in Wolaita Zone, Ethiopia
}

\author{
Markos Mathewos Alaro, Abraham Kebede \\ Department of Wolaita Language and Literature, Wolaita Sodo University, Wolaita Sodo, Ethiopia \\ Email address: \\ boke.tere7@gmail.com (M. M. Alaro),kebedeabraham9@gmail.com (A. Kebede) \\ To cite this article: \\ Markos Mathewos Alaro, Abraham Kebede. Relevance of Mother Tongue National Examinations to Mother Tongue Curriculum (Syllabus) \\ and Textbooks: The Case of Wolaita Language in Wolaita Zone, Ethiopia. Advances in Sciences and Humanities. \\ Vol. 6, No. 1, 2019, pp. 30-35. doi: 10.11648/j.ash.20200601.14
}

Received: August 10, 2019; Accepted: January 16, 2019; Published: January 21, 2020

\begin{abstract}
The objective of the study was to assess the relevance of mother tongue national examinations to MT curriculum, syllabus and textbooks. The participants of the study were teachers were 128. Three instruments were used to collect the data: questionnaire, interview and focus group discussion. Both qualitative and quantitative data analysis method were employed to arrive at conclusions. Thus, the research findings assured that grade-10 mother tongue (Wolaytato) national exam was not related to the textbook, syllabus and curriculum and most of the questions were not prepared from the text book, and curriculum and this affected student result in grade 10 Wolaytato national exam for many years. Accordingly, it was recommended that the school directors, wereda education office and the examination agency should work cooperatively to prepare the Wolaytato national exam according to the curriculum, text book and syllabus. The Examination Agency of Ethiopia and other stakeholders like Zone and south education department should follow that the exam includes various types of questions like listening, speaking, reading, grammar and other type of questions.
\end{abstract}

Keywords: Curriculum, Grade Ten, National Examination, Relevance, Syllabus

\section{Introduction}

The important role of language is beyond debate. It is a reasonable conclusion to say that success of any educational process relies much on the language to be used because it is instrumental in the transmission of knowledge Alieto 2018 [1]. Language is obviously the primary tool for effective communication in the classroom (Benson, 2005) as cited by Theresa B. 2015 [2]. This shows that to be effective in learning any subject matter in the classroom language is vital. Elementary students can better absorb lessons in mother tongue Garbes, 2012 [3]. Language is a part of human identity. Inhibiting mother tongue education is perceived as damaging to this identity, and thus, the demand for mother tongue education continues to exists Idris S. 2018 [4]. In relation to this Developing a mother tongue improves not only the mother tongue in the school, but also the aptitudes in the language that the majorities speak in the school Ozfidan, Machtmes, \& Demir, 2014 [5].
The language of instruction plays a crucial role in the learners' educational development, and is essential in the realization of communication and understanding between and among teachers and students Ejieh, 2004 [6]. Accordingly, language play a vital role in learning and teaching process. A study in the Philippines concluded that minority language students who gained literacy in their first language experienced higher academic achievement than students who learned in a second or third language Dekker, 2011 as cited by Alieto 2018 [7]. Walter (2011) argued that the use of mother tongue education is essential because it is "capable of producing proficient readers in 2-3 years" (Walter, 2011, p. 24) and will benefit learners who have average ability and potential [8]. However, Walter (2011) warned that not all sociolinguistic patterns are suitable for the use of mother tongue education [9].

Mallareddy (2012) on the other hand, emphasized the importance of the mother tongue education in early learning [10]. In his study, he found that neglected language skills 
development in the mother tongue resulted in the failure of the education system especially in the undergraduate level, which highlighted the need for the implementation of mother tongue based multilingual education (MTB-MLE) in the educational system. Thus, from all these point of views it easy to realize that mother tongue education up to the needed educational level is inevitable and it is the right of a particular ethnic group

As it is approved by United Nations Education, Scientific and Cultural Organization (UNESCO) and many countries, mother tongue instruction helps to improve students' performance in national examination and in school examinations. Learning one's mother tongue, having access to education, schooling in one's mother tongue, and non-discrimination in educational settings are some of the issues that are accepted as important for minorities Kaya, 2009 [11]. United Nations Education, Scientific and Cultural Organization (UNESCO) (2003a) espouses mother tongue instruction as a means of improving educational quality by building on the knowledge and experience of the learners and teachers [12]. First language instruction results in increased access and equity, improved learning outcomes, reduced repetition and dropout rates, socio cultural benefits and lower overall costs.

The term 'assessment' may be used in education to refer to any procedure or activity that is designed to obtain information about the knowledge, attitudes, or skills of a learner or group of learners Thomas Kellaghan, 2004 [13]. There is little disagreement that the examinations at the end of secondary education are of key importance in the education system of the country. Mother tongue national examination should be designed well so as to give confidence in the general conduct of the public school system. Good examination desiegn can lead to social cohession, it can help choose talent fairly, it can endenger trust in public instituations, it can give confidence in the general conduct of the public school system Greaney, V\&Kellaghan, T 1995 [14].

Standardized testing can be an important part of informed prescription. It can help raise teacher and school expectations of children of identifiable equity groups and it can assist I $n$ developmental diagnostic decisions by teachers Annette W. 2010 [15]. But if the testing and examination system becomes too 'high stakes' and too exhaustive, the risk is that the tests become a form of defacto curriculum, with teachers and schools ignoring or eliminating that which isn't tested and in this way the accountability context can deter informed professionalism in local curriculum and assessment practice, and therefore the achievement of improved quality and equity. Additionally there can be a constraining of the development and teaching of 'new capabilities' that are emerging in civic, community and workplace life.

Schleicher 2008 argues that an emphasis on centralized standards and curriculum mandates must be balanced against high levels of workforce curriculum professional decisionmaking [16]. When preparing mother tongue natoinal examination, its curriculum, textbooks and syllabus contents should carefully be taken in to considerations. Because if it is prepared out of these contents, the exam could not be valid and may affect students' performance. Invalid examination may direct students to wrong study habits. Thus, the relationship of teaching and testing is said to be backwash effect Nugussie Tamrat, 2002 [17]. Curricula and syllabi should be closely linked to performance standards and measure of outcomes. National goals for education, and outcomes statements that translate those goals into measurable objectives should provide the starting point for the development and implementation of curriculum United Nations Children's Fund (UNICEF, 2000) [18].

The national exam is expected to incorporate all language contents in textbook and curriculum including four language skills. There should also be adequate instructional materials for the effectiveness of grade-10 national exam. Regarding the shortage of instructional materials, TGE, 1994 also states that the supply of educational inputs such as teaching materials, textbook, educational technology and educational facilities are very inadequate [19]. Similarly, Chapman \& Mählck, 1993 argued that the relationships between inputs, processes, and outcomes need to be examined in the context of individual countries [20]. This is important to ensure the reliability and validity of the exam. However, most of the time, the examination of national exam is may not based on the curriculum and textbook. Thus, this study emphasize on assessing the relevance of mother tongue national examinations to MT curriculum, syllabus and textbooks.

\subsection{Objectives of the Study}

The objective of the study was to assess the relevance of mother tongue national examinations to MT curriculum, syllabus and textbooks.

\subsection{Scope of the Study}

It is possible to conduct research in different topics regarding mother tongue. However, due to time constraints, this study focused only on the Relevance of Mother Tongue National Examinations to MT Curriculum (Syllabus) and Textbooks. Geographically, it did not include all areas of Wolaita Zone; rather it focused only on some selected areas of Wolaita zone because of time and budget constraints.

\subsection{Abbreviations}

a. UNESCO: United Nations Education, Scientific and Cultural Organization.

b. UNICEF: United Nations Children's Fund.

c. MTB-MLE: Mother Tongue Based Multilingual Education.

\section{Methodology}

\subsection{The Research Design}

Both qualitative and quantitative research design was used in this study because it was suitable to investigate the relevance of national examination with reference to its curriculum, syllabus and textbook and the nature of the research also invites the researcher to use both of them. 


\subsection{Research Setting}

The research was conducted in Wolaita Zone which is one of thirteen zones found in SNNPR, Ethiopia. Wolaita is among highly populated areas in SNNPR having the population density of 385 per square kilometers Fancho \& Eyob 2011 [21]. Thus, the research was conducted in four Woredas of Wolayta Zone (Damot Gale, Humbo, Kindo Didaye, and Duguna Fango). These four weredas were purposively selected. The reason for selecting them purposively was the researchers' belief to get ample information from those weredas.

\subsection{Research Population}

The research was carried out in Wolaita Zone, SNNPR. The estimated sample population for this study were four Woredas i.e Humbo, Damot Gale, Kindo Didaye and Duguna Fango. From all these Woredas totally 104 students were selected using purposive sampling technique. This was mainly because the researchers wanted to participate those individuals who could offer rich information. From all weredas totally 8 teachers, 4 school principals, 4 weredas education experts and 8 parents were selected by using purposive sampling technique for study as sample size and this was the research population. Thus, the total population of the study were 128 .

\subsection{Sample Size and Sampling Technique}

The total population size of the study were 128 . In order to get this sample, the researcher used purposive sampling techniques for all population. The reason for using purposive sampling is to participate the research subjects who can provide rich information to the study. Among selected four Woredas, one secondary schools from each Woredas were selected purposively by taking in to account its accessibility to the area. From one selected schools in each Woredas, only grades 10 students were selected using purposive sampling so as to get those students who could offer ample data in the research project. From each school in selected Woredas, two sections were selected by using purposive sampling technique. This was based on information about the students that were given by the school principals so as to get adequate information from the students. From each section, 13 students were selected using purposive sampling techniques to involve both genders. Hence, 26 students were selected from each wereda and so that totally $104(26$ x 4) students were participated in the study. Two Wolayta Language teachers were selected purposely from each school in each Weredas. This was to get rich data from the subject teachers. Thus, totally 8 teachers were selected. In addition, 1 school director from each school were selected purposely and so that totally 4 school principals were involved in the study. In each wereda 1 wereda education experts were involved and totally 4 wereda education experts were engaged in study. 8 educated parents were also involved in the study. Hence, the total sample were 128 and this was to have ample data from the population.

\subsection{Tools for Data Collection}

Three instruments were used to collect data for this study. These were interview, focus group discussion and close ended questionnaire.

\subsection{Data Analysis}

In this study both qualitative and quantitative data analysis method were employed. This was because the data was gathered qualitatively and quantitatively by using interview, focus group discussion and questionnaire. The data gathered by using these three tools were analyzed qualitatively and quantitatively. During analysis priority was given to questionnaire then interview data to focus group discussion. The data gathered using three tools were analyzed in the form of text and in number in table. After that the result of data gathered by using three tools were triangulated.

\section{Results and Discussion}

Table 1. The relevance of mother tongue national examinations to MT curriculum, syllabus and textbooks.

\begin{tabular}{|c|c|c|c|c|}
\hline \multirow{2}{*}{ SN } & \multirow{2}{*}{ Items } & Yes & No & Sometimes \\
\hline & & $\mathbf{f}(\%)$ & $\mathbf{f}(\%)$ & f $(\%)$ \\
\hline 1.1 & In general do your Wolaytatto national exam relevant to the text book, syllabus and curriculum? & $23(35.94)$ & $28(43.75)$ & $13(20.31)$ \\
\hline 1.2 & Have you taken the Wolaytato reading skill test which is in syllabus or text book? & $34(53.13)$ & $12(18.5)$ & $18(28.13)$ \\
\hline 1.3 & $\begin{array}{l}\text { Have you taken Wolaytato listening skill test that makes you listen to various recorded materials } \\
\text { or the voice of the teacher and answer the questions from what you heard? }\end{array}$ & $22(34.78)$ & $30(46.88)$ & $12(18.75)$ \\
\hline 1.4 . & Have you taken Wolaytato writing skill test that makes you write about something? & $28(43.75)$ & $20(31.3)$ & $16(25)$ \\
\hline 1.5 . & Have you taken tests which evaluate your Wolaytato vocabulary knowledge? & $27(42.19)$ & $19(29.69)$ & $18(28.13)$ \\
\hline 1.7. & Have you ever taken Wolaytato spoken skill test? & $25(39.06)$ & $26(40.63)$ & $13(20.31)$ \\
\hline
\end{tabular}

$\mathrm{f}=$ frequency $\%=$ percentage.

As shown in table 1, item 1.1, 23 (35.94\%) respondents replied that Wolaytatto national exam relevant to the text book, syllabus and the curriculum. However, the majority of the participants about $28(43.75 \%)$ answered that Wolayttatto national exam did not relevant to the textbook, the syllabus and the curriculum and $13(20.31 \%)$ said that the exam sometimes relevant to the above materials.

The interview data also indicated that some questions in 
national exam are not relevant to the curriculum, syllabus and text book. Many questions are too general and not from the above materials. They also said that many questions did not emphasize on spoken and listening skills. Here were some of the responses from the research subjects: Most of the time the national exam is not related with curriculum, syllabus and textbooks. Those individuals who prepare national exam do not effectively take into consideration these materials and simply prepare examination from anywhere as much as they like. In addition to this, the exam should be prepared by those who has a good knowledge in curriculum and syllabus as well as experienced BA holders in Wolaita language and because of this the four language skills, especially listening and speaking skills are not considered when preparing national exam [P9, $10 \& 11,12 \& 15]$.

Some questions in national exam are related with the curriculum, syllabus and text book and several questions are out of those materials and this is because the way national exam prepared is not evaluated still now. Assigned teachers prepare the exam as much as it is suitable to them as no one evaluate the exam they prepared. The great problem is that when teachers are assigned to prepare the national exam, teachers experience and knowledge of the curriculum, syllabus and profession is not taken in to consideration rather teachers are selected based on who is benefited and who is not benefited i.e benefit oriented rather than experience and profession oriented [P1, 4, 7, 9, 14 \& 1].

Almost half of the national exam is not related with the curriculum, textbook and syllabus. National exam questions like proverbs and grammars and sentence arrangement are not from the text book rather those who prepare questions for the national exam prepare questions as they like [p1, p5, p13, p15 \& p16].

The focus group discussion data also indicated that some questions in national exam were not related with the textbook, syllabus, and curriculum. Several questions are too general. Questions like proverbs, grammars, sentence arrangements and questions related with children games are most of the time out of the textbooks, syllabus and curriculum and we need it to be not repeated for the future. Curriculum and text book preparation and design does not According to Arichley, 1977, curriculum developers should examine the acceptance of the new curriculum by teacher, parents and other community member [22]. The most impotent factors influencing the implementing of the curriculum is the qualification and experience of teachers, principals, and instructional materials.

Many questions are from the text books, but some questions are not from textbooks and so that it is possible to say that some questions are not related with the textbooks, curriculum and syllabus. Text book is very important for teaching learning process and the national exam should be prepared according to it. Textbooks are the single most important instructional tool in the classroom. They have had the largest and most obvious influence on curriculum to the extent of standardizing teaching and instructional practices Reed \& Verna, 1995 [23].

The data found from the three tools i.e. questionnaire, interview and focus group discussion, we can conclude that many questions in national exam were not relevant to the textbook, syllabus and curriculum.

As indicated in table 1 item 1.2, about 34 (53.13\%) of the students replied that they have taken Wolaytato reading skills in grade 10 Wolayttatto national exam and 12 (18.5\%) said that they have not taken Wolaytato reading skills in national exam. Again, 12 (28.13\%) replied that they have sometimes taken Wolaytato reading skills in grade-10 Wolayttatto national exam.

In table 1, item 1.3, 22 (34.78\%) of the respondents replied that they have taken Wolaytato listening exam test which enable them to listen various recorded materials or teachers' voice. But, many participants about $30(46.88 \%)$ said that they have not taken this skill in national exam in grade- 10 Wolayttatto national exam and only $12(18.75 \%)$ of them replied that they have taken it sometimes.

As demonstrated in table 1 , item 1.4. the majority of the research participants $28(43.75 \%)$ answered that they have taken the writing skill test that makes them write about something and about $20(31.3 \%)$ replied that they have not taken the reading skills in grade-10 Wolayttatto national exam. On the other hand, $16(25 \%)$ of them said that they have sometimes taken it.

As indicated in table 1, item 1.5, majority of the research subjects i.e., about $27(42.19 \%)$ answered that they have taken vocabulary questions in grade-10 Wolayttatto national exam. Again, 19 (29.69\%) of them said that they have not taken Wolaytato vocabulary questions national exam and about $18(28.13 \%)$ answered that they sometimes have taken Wolayato vocabulary questions.

Again in table 1 item 1.6, a lot of students about 32 (50\%) replied that they have taken the Wolayttatto national exam which tests their grammatical knowledge. Besides to this, about $18(28.13 \%)$ answered that they have not taken the national exam which tests this the knowledge of Wolaytato grammar and $18(21.88 \%)$ replied that they sometimes have taken the exam which tests this skill.

Moreover, in table 1, item 1.7, 25 (39.06\%) of the research participants answered that they have taken spoken skill test inngrade-10 Wolayttatto national exam. However, the majority of the respondents about $26(40.63 \%)$ said that they have not taken Wolaytato spoken skill in grade 10 Wolayttatto national exam and about 13 (20.31\%) said that they sometimes have taken this skill in national exam.

The above questionnaire data shows that student took writing and reading skill, vocabulary and grammar in grade 10 Wolaytato national exam. However, the interview and focus group discussion indicated that those questions were not related to Grade 10 Wolaytato curriculum, textbook and syllabus. Thus, according to the data, they were not relevant to the curriculum and textbook. Let us see some of the interview data below:

The national exam did not focus on Wolaytato language skills specially on speaking and listening skills. If you see many questions in national exam, almost all of them focus on grammar, proverbs and reading skills. you will never find 
Wolaytato listening skills and adequate Wolaytato spoken questions and the questions prepared also are not relevant to the curriculum and text book ( $P 3, P 9, P 10 \& P 12)$.

Questions related to writing and reading are appeared in national exam, but the exam was prepared from the textbook and curriculum and this affects students' result in grade-10 Wolaytato national exam (P1, P5 \& P11).

The results of focus group discussion also indicated almost similarly result as the questionnaire that the grade- 10 Wolayttatto national exam did not focus on Wolaytato listening and spoken skill. Many participants said that they have never taken Wolaytato listening skills in national exam and only few spoken skill questions appear in national exam. They also said that the exam in general and do not focus on textbook and curriculum. Heaton (1988:8) notes that "---it is usually extremely difficult to separate one skill from another, for the very division of the four skill, is an artificial one and the concept itself constitutes a vast oversimplification of the issues involved in communication [24]."

Based on the above data found from questionnaire, interview and focus group discussion, one can conclude that that the national exam did not focus on Wolaytato language skills, especially in listening and speaking which are found in Wolaytato textbook, curriculum and syllabus and the questions of national exam in general did not focus on Wolaytato curriculum and textbook.

\section{Conclusions}

Based on the findings of the study the following conclusions were made:

1. The study disclosed that preparing grade- 10 mother tongue (Wolaitato) national which were not related to the textbook, syllabus and curriculum and most of the questions were not prepared from the text book, and curriculum and this affected student result in grade 10 Wolaytato national exam for many years.

2. The study also indicated that gade- 10 Wolaytato national exam did not focus on language skills especially in listening and speaking. Most of the questions were grammar and grammar related. Although many questions seems different, they were grammar items which were asked in different ways.

3. The study approved that Grade-10 Wolayta language national exam were slightly emphasized on writing skills and reading skills. However, it needs more attention and work by the teachers and students as well as other stakeholders so as to strengthen it.

4. Furthermore, the study clearly assured that grade 10 Wolayta language national exam was emphasized on vocabulary items and this also shows for teachers and other stake holders to pay attention to prepare integrated questions in Wolayta language national examination.

\section{Recommendations}

Based on the above conclusions, the following recommendations were made.

1. The school directors, wereda education office and the Ethiopian national examination agency should work cooperatively to prepare the Wolaytato national exam according to the curriculum, text book and syllabus.

2. The examination agency and FDRE ministry of education should follow and realize that Wolaytato national exam is prepared according to the curriculum, text book and syllabus. They should carefully follow and make corrections before the distribution of the exam if it is not designed according to aforementioned instructional materials.

3. The examination Agency of Ethiopia and other stakeholders like Zone and southern Ethiopia education department should follow that the exam includes various types of questions like listening, speaking, reading, grammar and other type of questions.

4. The wereda and Zone education department in collaboration with Southern Ethiopia education department should give training for those who are proposed to prepar Grade 10 Wolaytato national exam so as to capacitate them to design various types of questions according to curriculum and syllabus.

\section{References}

[1] Alieto (2018). Language shift from English to mother tongue: Exploring language attitude and willingness to teach among pre-service teachers: TESOL International Journal Vol 13 (3) https://www.researchgate.net/publication/330344045.

[2] Arichley, K. (1977). Hand book of Curriculum Education Paris: UNESCO, International Institute for Educational Planning.

[3] Benson (2005) Mother Tongue Based Teaching and Education for Girls UNESCO Advocacy. Retrieved on February 3, 2015 from

http://www.unescobkk.org/education/multilingualeducation/re sources/mle-advocacy-kit/.

[4] Chinapah, V. (1997). Handbook on monitoring learning achievement. Towards capacity building. Paris: UNESCO.

[5] Chapman, D. W., \& Mählck, L. O. (1993). Improving educational quality through better use of information. In D. W. Chapman \& L. O. Mählck (Eds), From data to action: Information systems in educational planning (pp 1-22). Paris: International Institute for Educational Planning.

[6] Education Certificate English Examination. (Published M. A Thesis): Addis Ababa University.

[7] Ejieh, M. U. (2004). Attitudes of student teachers towards teaching in mother tongue in Nigerian primary schools: Implications for planning. Language, Culture and Curriculum, 17 (91), 73-81. doi: 10.1080/07908310408666683.

[8] Fancho \& Eyob (2011). The Economic, Social and Political History of Wolaita until 1974. Wolaita Sodo.

[9] Fleming, Harold C. (1976) Omotic overview. In: M. L. Bender (ed.) The Non-Semitic languages of Ethiopia, 299-323. East Lansing: African Studies Center, Michigan State University. 
[10] Garbes, L. (2012) Mother Tongue based Education. Cultural Survival Retrieved January 21, 2014. Retrieved from http://www.culturalsurvival.org/news/mother-tonguebasededucation- Philippines.

[11] Heaton, J. B. (1988) Writing English Language Tests, London: Longman.

[12] Idris (2018). A look at mother tongue education in the context of the right to education: Academic journal V 13 (9) pp 343353, DOI: 10.5897/ERR2018.3485retrievedfrom http://www.academicjournals.org/ERR.

[13] Kaya N (2009). Forgotten or assimilated? Minorities in the education system of turkey. Minority Rights Group International. Retrieved on 7 January 2018 from http://minorityrights.org/publications/forgotten-orassimilatedminorities-in-the-education system-of-turkey-march-2009/.

[14] Kellaghan, T. (2003). Local, national, and international levels of system evaluation. Introduction. In T. Kellaghan \& D. L. Stufflebeam (Eds), International handbook of educational evaluation (pp. 873-882). Dordrecht: Kluwer Academic.

[15] Mallareddy, K. (2012). Poor Performance of Communicative Skills in Mother Tongue Resulted in Failure of Under Graduate Students in Indian University Examinations. International Journal of Social Science and Humanity, 2 (6), 539.

[16] Nigusie Tamirat (2002). The Content Validity of the Ethiopian General Secondary.

[17] Ozfidan, B., Machtmes, K., \& Demir, H. (2014). Sociocultural Factors in Second Language Learning: A Case Study of Adventurous Adult Language Learners. European Journal of Education Research, 3 (4), 185-191. https://doi.org/10.12973/eu-jer.3.4.185.

[18] Pattanayak, D. P. (2003) multilingual contexts and their ethors. In A. Ouane (ed.) towards multilingual culture of education, 129-139. Humburg: UNESCO Institute for Education Roy.
[19] Reed, J. S \& Verna E. Bergamann, (1995). In classroom: An Introduction to Education 2nded. Washington, D. C: McGrawHill Inc.

[20] Sezeper G. (1984). Mother Tongue Language Policy and Education. Prospects 14/1/, 63-75.

[21] Theresa. B (2015). Current perspectives on mother - tongue based instruction in the newly implemented $\mathrm{k}$ to 12 curriculum of the philippines: British Journal of Education, Vol. 3, No. 9, pp. 51-66, September 2015.

[22] Thomas Kellaghan (2004) Public examinations, national and international assessments, and educational policy, Educational Research Centre, St Patrick's College, Dublin.

[23] TGE (1994) Ethiopian Education and Training Policy. Addis Ababa: Transitional Government of Ethiopia.

[24] UNESCO (2003a). Education in a multilingual world. UNESCO Education Position Paper. Paris: Retrieved January 15, 2009 from: http://unesdoc.unesco.org/images/0012/001297/129728e.pdf.

[25] UNICEF (2000). Determining Quality in Education: Paper Presented by UNICEF at a Meeting of the International Working Group on Education, Florence, Italy, June 2000 UNICEF.

[26] Walter, S., \& Dekker, D. (2011). Mother tongue instruction in Lubuagan: A case study from the Philippines. International Review of Education, 57 (5-6), 667-683.

[27] Walter, S. L. (2011). Mother tongue-based education in developing countries: Some emerging insights. Retrieved November 16, 2015 from https://www.researchgate.net.

[28] Annette W. (2010). Curriculum and Syllabus Design: Queensland University of Technology, https://www.researchgate.net/publication/27473672. 